\title{
Pengaruh Lokasi dan Kualitas Pelayanan Terhadap Loyalitas Konsumen pada Fotocopy Anugrah Rengat
}

\author{
${ }^{1}$ Hermanto, ${ }^{2}$ Roky Apriansyah, ${ }^{3}$ Khusnul Fikri, ${ }^{4}$ Albetris \\ ${ }^{1,2,3}$ Sekolah Tinggi Ilmu Ekonomi Indragiri (Stie-I) Rengat \\ ${ }^{4}$ Universitas Batanghari Jambi
}

Correspondence email: hermanto@stieindragiri.ac.id, rokyapriansyah@stieindragiri.ac.id,khusnul_fikri@stieindragiri.ac.id, albetris90@gmail.com

\begin{abstract}
This research was conducted on AnugrahPhotocopy in Rengat with the aim to determine the effect of Location and Service Quality to Consumer Loyalty atRengatPhotocopy in Rengat. Sampling was done by random sampling method with 98 samples as respondents. The analytical method used is a quantitative descriptive method, data analysis with partially and simultaneously act (multiple linear regression analysis with the help of the IBM SPSS Stastic program version 21.0). From the results of the research, obtained a regression equation that is $Y=9,881+0,243 X 1+0,321 X 2$, it can be seen that Location and Service Quality has a positive influence to Consumer Loyalty atAnugrahPhotocopy in Rengat. In addition, simultaneous testing (Test F), has been obtained F count $>F$ table that is equal to 6.311> 3.09. So that the two independent variables namely location and service quality together have a positive and significant effect on the dependent variable, namely Consumer Loyalty atAnugrahPhotocopy in Rengat. While the Partial Regression Test ( $t$ test) shows that location variables significantly influence to Consumer Loyalty at Anugrah Photocopyin Rengat, $t$ arithmetic $>t$ table of 2.554> 1.98525. Variable service quality is more dominant significant effect to Consumer Loyalty at Anugrah Photocopyin Rengat namely t arithmetic > t table of 3.447> 1.98525. In addition, the results of the multiple correlation coefficient is 0.742 which shows the level of relationship between all independent variables to the dependent variable in this research is in the criteria of high relationship closeness. The magnitude of the effect caused by these three variables together affect the consumer loyalty variable with a percentage of 55.1\%. While 44.9\% is influenced by other factors not included in this study.
\end{abstract}

Keywords: Location; Service Quality; Consumer Loyality

\section{PENDAHULUAN}

Saat ini kemajuan perekonomian di Indonesia secara perlahan - lahan mulai berdampak terhadap kehidupan masyarakatnya. Adanya peningkatan status sosial dan ekonomi masyarakat berakibat pula pada perubahan perilaku serta gaya hidup. Perubahan tersebut pada akhirnya akan mempengaruhi selera kepuasan terhadap suatu produk. Masyarakat menginginkan produk dan layanan berkualitas yang sesuai dengan kebutuhan mereka. Agar dapat bersaing, bertahan hidup, dan berkembang perusahaan dituntut untuk mampu memenuhi keinginan dan kebutuhan masyarakat yang berorientasi pada kepuasan konsumendan menjadikan konsumen loyalitas tehadap perusahaan itu. Produk dan jasa yang tidak memenuhi kriteria kualitas konsumen dengan sangat mudah ditinggalkan dan akhirnya konsumen beralih ke perusahaan lain. Untuk mengantisipasi hal tersebut tentunya perusahaan dituntut untuk mengutamakan perluasan produk dan pelayanan yang berorientasi pada kepuasan konsumen.

Kualitas pelayanan yang baik di dalam suatu perusahaan, akan menciptakan kepuasan bagi para konsumennya. Setelah konsumen merasa puas dengan produk atau jasa yang diterimanya, konsumen akan membandingkan pelayanan yang diberikan. Apabila konsumen merasa benar - benar puas, mereka akan membeli ulang serta memberi rekomendasi kepada orang lain untuk membeli di tempat yang sama. Oleh karena itu perusahaan harus memulai memikirkan pentingnya pelayanan pelanggan secara lebih matang melalui kualitas pelayanan, karena kini semakin disadari bahwa pelayanan (kepuasan pelanggan) merupakan aspek vital dalam rangka bertahan dalam bisnis dan memenangkan persaingan.

Bisnis penggandaan, penjualan ATK dan fotocopy merupakan industri yang berkembang secara cepat dan dinamis dalam kehidupan modern di kota-kota, karena hampir setiap aspek kehidupan kota memerlukan jasa penggandaan dan fotocopy, baik dalam skala besar maupun dalam skala kecil. Sehinga pada kabupaten Indragiri Hulu banyak usaha fotocopy dan potocopy yang berdiri, perkembangan ini mengakibatkan semakin tingginya persaingan usaha diantara mereka.

Kondisi kompetensi yang semakin ketat, membuat para pelaku pasar dan produsen berlomba untuk memenangkan persaingan yang sangat ketat ini. Salah satu upaya untuk merebut pangsa pasar yaitu dengan lokasi usaha yang strategis. Lokasi adalah letak usaha atau penjualan barang yang ditentukan perusahaan 
sehingga dapat dijangkau oleh konsumen. Lokasi yang strategis diartikan sebagai letak yang dapat dijangkau oleh konsumen dan memberikan berbagai kemudahan bagi konsumen dalam memenuhi kebutuhannya. Lokasi yang mudah dijangkau oleh konsumen akan menjadi pilihan utama dalam mealkukan pembelian. Ada berbagai faktor penting untuk menentukan lokasi pemasaran khususnya pada perusahaan jasa, yang dapat mempengaruhi loyalitas konsumen. Faktor-faktor yang meliputi potensi pasar, kondisi lingkungan disekitar wilayah pemasaran, kelancaran arus transportasi, fasilitas parkir yang tersedia dan adanya lembaga kegiatan lain yang berada dilokasi pemasaran seperti perusahaan-perusahaan lain yang berpotensi melaksanakan kegiatan opersaionalnya. Salah satu bisnis atau usaha yang juga merasakan dampak perubahan selera kepuasan konsumen terhadap suatu produk saat ini adalah bisnis fotocopy atau fotocopi. Kualitas produk serta pelayanan yang ditawarkan pun beraneka macam, dengan begitu setiap perusahaan akan memiliki ciri dan keunggulan tersendiri yang nantinya akan menjadi nilai positif bagi perusahaan tersebut. Hal inilah yang kemudian menjadi problem bagi perusahaan karena baik pemilik maupun karyawan dituntut untuk menciptakan strategi inovasi agar mampu bersaing dan unggul dibandingkan dengan kompetitor-kompetitornya.

Fotocopy Anugrah Rengat merupakan salah satu perusahaan fotocopy yang telah beroperasi di Pematang Reba sejak tahun 1999. Banyak perusahaan lain yang juga beroperasi di sekitar perusahaan ini, yaitu beberapa fotocopy yang sejenis, rental internet, minimarket, dan toko-toko lainnya, selain itu perusahaan ini juga dekat dengan Perkantoran. Fotocopy Anugrah Rengat hanya melakukan kegiatan produksi seperti penjilidan sederhana dan ketik manual pada awalnya, tetapi seiring dengan berjalannya waktu, maka permintaan pelanggan semakin komplit sehingga perusahaan ini pun meningkatkan layanannya dan berupaya mengikuti tren teknologi fotocopy dengan menyediakan mesin foto-copy, mesin cetak offset, laminating, alat untuk menjilid ring, jilid lux, komputer, printwarna dan mesin scanner serta kelengkapan fotocopy lainnya. Fotocopy Anugrah Rengat, dimana sebagai salah satu perusahaan fotocopy atau potocopi yang ada di daerah Pematang Reba juga memiliki strategi dan keunggulan yang berbeda dibanding pesaing yang ada. Perusahaan harus mengetahui faktor - faktor yang mempengaruhi kepuasan pelanggannya agar tercipta loyalitas dari konsumen serta dapat melakukan perbaikan dan inovasi yang diharapkan dapat meningkatkan kepuasan pelanggan setelah melakukan transaksi di Perusahaan Fotocopy Anugrah Rengat. Pada perusahaan selain pelayanan pada pelanggan dalam bentuk fisik, juga dibutuhkan pelayanan non fisik, yaitu kemampuan berkomunikasi dari setiap karyawan yang bertugas. Kemampuan berkomunikasi yang dimaksudkan dalam hal ini adalah bagaimana karyawan tersebut membantu setiap pembeli yang datang berkunjung, sehingga memudahkan pembeli dalam mendapatkan pelayanan sesuai kebutuhannya. Selain itu, karyawan juga harus memiliki sikap empati, ramah dan sopan, serta dapat memberikan pelayanan dengan cepat kepada setiap pengunjung. Dalam hal pelayanan pada pelanggan, Fotocopy Anugrah Rengat memiliki beragam permasalahan, di mana saat ini masih terdapat karyawan yang kurang ramah kepada konsumen dan karyawan yang bekerja dengan baik hanya ketika diawasi saja. Selain itu, kurangnya respon karyawan terhadap para pengunjung yang datang, hal ini diakibatkan karena kurang memadainya jumlah karyawan yang melayani di dalam toko dengan jumlah pengunjung yang datang. Sehingga mengakibatkan pengunjung tersebut memutuskan untuk pergi karena merasa tidak dilayani. Fotocopy Anugrah Rengat sebagai salah satu dari banyak fotocopy di Pematang Reba yang harus menghadapi dinamika persaingan yang ketat dengan fotocopy lainnya. Dengan semakin meningkatnya persaingan, maka semakin penting peranan lokasi yang strategis dan Kualitas pelayanan pada pelanggan dalam memasarkan barang atau jasa yang diperdagangkan. Sedangkan memilih lokasi yang strategis perusahaan untuk berdagang dan kualitas pelayanan pada pelanggan merupakan bagian dari pemasaran sebagai alat untuk membangun loyalitas konsumen dan turut menentukan suksesnya suatu perusahaan agar dapat bertahan, bersaing serta menguasai pasar. Berdasarkan hasil wawancara yang peneliti lakukan terhadap Fotocopy Anugrah Rengat, pemilik toko menyebutkan bahwa pada tahun ini jumlah konsumen yang berkunjung untuk berberlanja ditoko ini semakin menurun, berikut jumlah pengunjung yang membeli di Fotocopy Anugrah Rengat dari tahun 2014 s/d 2018. 
Tabel 1.

Jumlah Pengunjung yang membeli di Fotocopy Anugrah Rengat tahun $2011 \mathrm{~s} / \mathrm{d} 2015$

\begin{tabular}{cccc}
\hline No. & Tahun & Jumlah Pengunjung (Orang) & Persentase $(\%)$ \\
\hline 1. & 2014 & 5.110 & $(4,11)$ \\
2. & 2015 & 4.900 & 4,08 \\
3. & 2016 & 5.100 & $(9,80)$ \\
4. & 2017 & 4.600 & $(5,02)$ \\
5. & 2018 & 4.380 & \\
\hline
\end{tabular}

Sumber : Fotocopy Anugrah Rengat

Tabel 1, tahun 2014 ini jumlah pengujung di Fotocopy Anugrah Rengat sebanyak 5.110 orang, tahun 2015 ini jumlah pengujung mengalami penurunan dari tahun sebelumnya di Fotocopy Anugrah Rengat sebanyak 4900 orang, tahun 2016 ini jumlah pengujung mengalami peningkatan dari tahun sebelumnya di Fotocopy Anugrah Rengat sebanyak 5.100 orang, tahun 2017 ini jumlah pengujung mengalami penurunan di Fotocopy Anugrah Rengat sebanyak 4.600 orang dan tahun 2018 ini jumlah pengujung mengalami penurunan lagi di Fotocopy Anugrah Rengat sebanyak 4.380 orang. Jumlah pengunjung yang makin tahun ketahun menurun ini mengakibatkan penjualan pada Fotocopy Anugrah Rengat mengalami perubahan dan turun. Adapun data penjualan selama tahun 2014 s/d 2018 pada Perusahaan Fotocopy Anugrah Rengat dapat dilihat pada tabel berikut ini.

Tabel 2

Penjualan Fotocopy Anugrah Rengat tahun 2014 s/d 2018

\begin{tabular}{cccc}
\hline No. & Tahun & Hasil Penjualan $(\mathrm{Rp})$ & Persentase $(\%)$ \\
\hline 1. & 2014 & 412.435 .000 & - \\
2. & 2015 & 390.114 .000 & $(05,72)$ \\
3. & 2016 & 478.378 .000 & 18,45 \\
4. & 2017 & 421.923 .000 & $(13,38)$ \\
5. & 2018 & 385.745 .000 & $(09,38)$ \\
\hline
\end{tabular}

Sumber : Fotocopy Anugrah Rengat

Tabel 2, pada tahun 2014 hasil penjualan Fotocopy Anugrah Rengat yaotu sebesar Rp. 412.435.000, tahun 2015 hasil penjualan menurun sebesar Rp. 390.114.000,- dengan persentase penurunan sebesar 5,72\% dari tahun sebelumnya. Tahun 2016 hasil penjualan meningkat yaitu sebesar Rp. 478.378.000,- dengan persentase kenaikan dari tahun sebelumnya yaitu sebesar 18,45\%. Tahun 2017 hasil penjualan pada Fotocopy Anugrah Rengat mengalami penurunan kembali yaitu sebesar Rp. 421.293.000 dengan persentase penurunan 13,38\%. Tahun 2018 hasil penjualan mengalami penurunan kembali pada Fotocopy Anugrah Rengat yaitu Rp. 385.745.000 dengan persentase 9,38\%. Tujuan penelitian ini adalah untuk mengetahui pengaruh Kualitas Pelayanan secara parsial berpengaruh signifikan terhadap Loyalitas Konsumen pada Fotocopy Anugrah Rengat.

\section{Telaah Pustaka dan Hipotesis Loyalitas Konsumen}

Secara harfiah loyal berarti setia, atau loyalitas dapat diartikan sebagai suatu kesetiaan. Kesetiaan ini diambil tanpa adanya paksaan, tetapi timbul dari kesadaran sendiri pada masa lalu. Usaha yang dilakukan untuk menciptakan kepuasan konsumen lebih cenderung mempengaruhi sikap konsumen. Sedangkan konsep loyalitas konsumen lebih menerangkan kepada perilaku pembelinya. Loyalitas konsumen adalah kesetiaan konsumen terhadap perusahaan, merek maupun produk (Dharmesta et.al, 2005:24). Loyalitas konsumen adalah sikap menyenangi terhadap suatu merek yang dipresentasikan dalam pembelian yang konsisten terhadap merek itu sepanjang waktu (Huriyati, 2005:96).

Loyalitas konsumen adalah komitmen pelanggan terhadap suatu merek, toko atau pemasok berdasarkan sifat yang sangat positif dalam pembelian jangka panjang (Tjiptono, 2008:123). Dapat disimpulkan bahwa loyalitas konsumen adalah loyalitas konsumen adalah suatu perilaku yang ditunjukan dengan pembelian rutin yang didasarkan pada unit pengambil keputusan, serta merupakan suatu komitmen untuk tetap menggunakan suatu produk atau jasa tanpa terpengaruh oleh usaha yang dilakukan oleh perusahaan pesaing 


\section{Lokasi}

Menentukan lokasi tempat untuk setiap bisnis merupakan suatu tugas penting bagi pemasar, karena keputusan yang salah dapat mengakibatkan kegagalan sebelum bisnis dimulai. Memilih lokasi berdagang merupakan keputusan penting untuk bisnis yang harus membujuk pelanggan untuk dating ke tempat bisnis dalam pemenuhan kebutuhannya. Pemilihan lokasi mempunyai fungsi yang strategis karena dapat ikut menentukan tercapainya tujuan badan usaha. Lokasi lebih tegas berarti tempat secara fisik. Lokasi adalah letak atau toko pengecer pada daerah yang strategis sehingga dapat memaksimumkan laba (Dharmesta et.al, 2005:49). Lokasi adalah tempat perusahaan beroperasi atau tempat perusahaan melakukan kegiatan untuk menghasilkan barang dan jasa yang mementingkan segi ekonominya (Buchari, 2009:48). Lokasi merupakan tempat usaha yang sangat mempengaruhi keinginan seseorang konsumen untuk datang dan berbelanja (Tjiptono, 2009:87). Lokasi adalah tempat perusahaan beroperasi atau tempat perusahaan melakukan kegiatan untuk menghasilkan barang dan jasa yang mementingkan segi ekonominya (Kertajaya, 2006:93). Lokasi adalah tempat di mana perusahaan harus bermarkas melakukan operasi (Lupiyoadi, 2013:81). Jadi lokasi dapat disimpulkan adalah tempat yang berhubungan dimana perusahaan akan didirikan dan dilaksanakan.

\section{Kualitas Pelayanan}

Kualitas layanan didefinisikan sebagai excellent, superior atau keunggulan layanan yang diterima oleh pelanggan relatif terhadap apa yang diharapkan oleh pelanggan. Persepsi pelanggan merupakan penilaian subjektif dari layanan aktual yang dialami oleh pelanggan. Hubungan antara dua konsep, harapan pelanggan dan persepsi pelanggan, memainkan peranan penting dalam pemasaran jasa (service marketing). Dengan meningkatnya persaingan yang terus berkelanjutan, kualitas pelayanan (service quality) menjadi sangat penting peranannya dalam ruang lingkup bisnis. Bahwa konsumen menciptakan harapan-harapan layanan dari pengalaman masa lalu, komunikasi word of mouth dan iklan. Konsumen membandingkan jasa yang dipersepsikan dengan jasa yang diharapkan. Konsumen akan kecewa jika jasa yang dipersepsikan berada dibawah jasa yang diharapkan, demikian pula sebaliknya.

Kuliatas pelayanan didefinisikan sebagai ukuran seberapa baik tingkat pelayanan yang diberikan, serta sesuai dengan ekspektasi pelanggan. Artinya bahwa kualitas pelayanan bisa diwujudkan melalui pemenuhan kebutuhan dan keinginan pelanggan serta ketepatan penyampaiannya untuk mengimbangi harapan pelanggan (Tjiptono, 2009:121). Kualitas pelayanan adalah pelayanan yang diberikan kepada pelanggan sesuai dengan standar pelayanan yang telah dibakukan sebagai pedoman dalam memberikan layanan (Kotler, 2009:116). Berdasarkan pengertian di atas bahwa kualitas pelayanan merupakan suatu layanan yang diberikan organisasi itu harus menjamin efisiensi dan keadilan serta harus memiliki kualitas yang mantap. Kualitas merupakan harapan semua orang atau pelanggan. Selanjutnya untuk mengimplementasikan kualitas pelayanan adalah merubah paradigma. Perubahan paradigma tersebut tidak hanya dengan alur atau struktur berfikir (mindset) para pelaku penyedia pelayanan namun juga di wujudkan dalam tataran realitas seperti organisasi, sistem pertanggung jawaban, proses dan sumber daya organisasi. Beberapa pengertian kualitas pelayanan di atas maka kualitas pelayanan merupakan suatu manajemen strategis yang di berikan petugas pelayanan dan memberikan kepuasan terhadap konsumen

\section{Hipotesis}

Diduga kualitas pelayanan secara parsial berpengaruh signifikan terhadap loyalitas konsumen pada Fotocopy Anugrah Rengat.

\section{METODE PENELITIAN}

Penelitian ini dilakukan secara langsung pada Fotocopy Anugrah Rengat di jalan Datuk Hasyim Kelurahan Kampung Besar Seberang Rengat. Data yang dikumpulkan adalah data primer dan sekunder. Populasi dalam penlitian ini adalah seluruh konsumen yang berbelanja di Fotocopy Anugrah Rengat Tahun 2015 sebanyak 4380 konsumen. Jadi untuk mempermudah dalam memperoleh persentase jawaban tersebut, peneliti hanya mengambil sampel dengan menggunakan metode random sampling secara acak dengan menggunakan rumus slovin yang diangkat sebagai bahan sampel dalam penelitian ini. 
$n=\frac{N}{1+N e^{2}}$

Dimana $: \mathrm{n}=$ jumlah sampel; $\mathrm{N}=$ jumlah populasi; $\mathrm{e}=$ batas toleransi kesalahan

$n \frac{4380}{1+4380(10 \% 6)^{2}}=97,77$ (dibulatkan menjadi 98)

Sampel yang penulis ambil dalam penelitian ini adalah sebanyak 98 responden.

Dalam melakukan analisis data terhadap data yang telah didapatkan, penulis menggunakan metode persamaan regresi linier berganda, dengan menggunakan program (Statistic For and Service Solution) SPSS Window yaitu suatu metode Statistik yang digunakan untuk mengetahui hubungan antara dua variabel yaitu variabel bebas (Lokasi dan Kualitas Pelayanan) dan Variabel terikat (Loyalitas Konsumen). Hubungan antara keduanya ini akan diformulasikan kedalam persamaan.

$\mathrm{Y}=\mathrm{a}+\mathrm{b}_{1} \mathrm{X}_{1}+\mathrm{b}_{2} \mathrm{X}_{2}+\mathrm{b}_{3} \mathrm{X}_{3}+\mathrm{e}$

\section{HASIL DAN PEMBAHASAN}

Hasil dari regresi linear berganda penelitian ini adalah yaitu $Y=9,881+0,243 X 1+0,321 X 2$, dimana kedua variabel bebas memiliki hubungan pengaruh dan positif. Berdasarkan hasil rekapitulasi kuesioner penelitian, dapat diketahui tanggapan 98 responden mengenai Lokasi dan Kualitas Pelayanan berkategori baik. Hal ini menunjukkan bahwa pada dasarnya Lokasi dan Kualitas Pelayanan pada pada Fotocopy Anugrah Rengat baik dan mempengaruhi Loyalitas konsumen sebesar 55,1\%. Selain itu dapat disimpulkan bahwa variabel kualitas pelayanan lebih berpengaruh terhadap loyalitas konsumen dibandingkan dengan variabel lokasi pada Fotocopy Anugrah Rengat. Pada hasil uji F menunjukkan kedua variabel independent memiliki pengaruh yang positif dan signifikan terhadap Loyalitas Konsumen pada Fotocopy Anugrah Rengat. Untuk itu Pimpinan Fotocopy Anugrah Rengat perlu memperhatikan hal-hal tersebut terhadap Loyalitas Konsumen.

\section{SIMPULAN}

Hasil dari regresi diperoleh persamaan yaitu $\mathrm{Y}=9,881+0,243 \mathrm{X} 1+0,321 \mathrm{X} 2$. Artinya, jika nilai koefisien Lokasi $\left(\mathrm{X}_{1}=0,243\right)$ dan nilai koefisien Kualitas Pelayanan $\left(\mathrm{X}_{2}=0,321\right)$ maka nilai variabel Loyalitas Konsumen (Y) adalah sebesar 9,881, Jika nilai koefisien Lokasi ( $\left.\mathrm{X}_{1}\right)$ mengalami kenaikan/peningkatan 1 point sedangkan variabel independent lainnya tetap, maka Loyalitas Konsumen (Y) akan meningkat sebesar 0,243, dan jika nilai koefisien Kualitas Pelayanan $\left(\mathrm{X}_{2}\right)$ mengalami kenaikan/peningkatan 1 point sedangkan variabel independent lainnya tetap, maka Loyalitas Konsumen (Y) akan meningkat sebesar 0,321. Oleh karena itu terjadi hubungan yang positif antara Lokasi dengan Loyalitas Konsumen. Serta terdapat pula hubungan yang positif antara Kualitas Pelayanan dengan Loyalitas Konsumen.

\section{DAFTAR PUSTAKA}

Adhimas, Putra Samuel. 2013. pengaruh lokasi, persepsi harga dan kualitas pelayanan terhadap loyalitas pelanggan di toko sari kaligawe, semarang. Fakultas Ekonomika dan Bisnis Universitas Semarang.

Ariyadi, Fajar. 2011. pengaruh lokasi dan kualitas pelayanan terhadap loyalitas konsumen pada BPR Bank Pasar Boyolali. Fakultas Ekonomi Universitas Muhammadiyah Surakarta.

Assauri, Sofjan. 2007. Manejemen Pemasaran. Rajawali Pers. Jakarta

Buchari, Alma. 2009. Manajemen pemasaran dan Pemasaran Jasa, Cetakan Kedelapan. Alfabeta. Bandung.

Dharmesta dan Irawan. 2005. Manajemen Pemasaran Modren Edisi Kedua. Liberty. Yogyakarta.

Ghozali, Imam. 2007. Aplikasi Analisis Multivariate Dengan Program SPSS. BP-Universitas Diponogoro. Semarang

Griffin, Jill. 2005. Customer Loyalty, Edisi Revisi. Erlangga. Jakarta.

Hasan, Ali. 2008. Marketing. MedPres. Yogyakarta 
Huriyati, Ratih. 2005. Bauran Pemasaran dan Loyalitas Konsumen. Alfabeta. Bandung.

Kertajaya, Hermawan. 2006. Marketing Plus 2010 : Siasat memenangkan persaingan global. PT. Gramedia Pustaka Utama. Jakarta.

Kotler, Philip dan Keller Kevin Lane. 2009. Manajemen Pemasaran, edisi 13 jilid 1. PT. Indeks Kelompok Gramedia. Jakarta.

Lupiyoadi, Rambat. 2013. Manajemen Pemasaran Jasa. Salemba Empat. Jakarta.

Ma’ruf, Hendri. 2005. Pemasaran Ritel. PT Gramedia Pustaka Utama. Jakarta

Maholtra, Naresh K. 2009. Riset Pemasaran Pendekatan Terapan Jilid 1. PT. Index. Jakarta.

Ningsih, Diyan. 2013. Pengaruh Pelayanan, Harga dan Lokasi terhadap Kepuasan Pelanggan serta dampaknya pada Loyalitas Pelanggan CONVENIENCE STORE 7-ELEVEN UIN CIPUTAT. Jurusan Manajemen Fakultas Ekonomi dan Bisnis Universitas Islam Negeri Syarif Hidayatullah. Jakarta.

Nurul, Himawati Isnaini. 2011. Pengaruh Kualitas Pelayanan dan Lokasi Terhadap Loyalitas Konsumen Dengan Kepuasan Pelanggan Sebagai Varibel Intervening Di Wisata Kuliner Malam Galabo Solo. Under Graduates thesis Fakultas Ekonomi Universitas Negeri Semarang.

Peter, J. Paul dan Donelly, H. James. 2007. Perilaku Konsumen dan Strategi Pemasaran. Jilid VII. Erlangga. Jakarta

Tjiptono, Fandy. 2005. Strategi Pemasaran edisi Kedua. Andi Offset. Yogyakarta.

Tjiptono, Fandy. 2008. Strategi Bisnis Pemasaran. Andi Offset. Yogyakarta.

Tjiptono, Fandy. 2009. Strategi Pemasaran Jasa. Andi Offset. Yogyakarta.

Ulfa, Maria. 2012. Pengaruh kualitas pelayanan, harga dan lokasi terhadap loyalitas konsumen di penginapan Mega Syaria'ah Semarang. Fakultas Syari'ah Institut Agama Islam Negeri Walisongo Semarang.

Umar, Husen. 2009. Metode Penelitian Untuk Skripsi dan Tesis Bisnis Edisi Kedua. Rajawali Pers. Jakarta. 